\title{
COกE)-(OES
}

CIÊNCIA E TECNOLOGIA

\section{RECICLAGEM DE ÓLEOS E GORDURAS RESIDUAIS: PERCEPÇÃO DO IMPACTO AMBIENTAL POR MORADORES DE CONDOMÍNIO RESIDENCIAL EM FORTALEZA/CE}

\author{
BeAtriz FeItoza Rocha, ERIKA DA JUsta TEIXEIRA Rocha \\ Instituto Federal de Educação, Ciência e Tecnologia do Ceará - IFCE \\ <beatrizfeitozarocha@hotmail.com>.<erikadajusta@gmail.com> \\ $10.21439 /$ conexoes.v15i0.2179
}

\begin{abstract}
Resumo. Considerando que o descarte de óleos e gorduras causa diversos impactos negativos, especialmente com a poluição da água, do solo e impactos sobre a infraestrutura de saneamento, é necessário que a população tome conhecimento das formas de reuso e destinação adequados desse resíduo. Assim, este trabalho teve como objetivo promover a mudança de hábitos dos sujeitos residentes em um condomínio da cidade de Fortaleza a partir de um treinamento e da realização de um diagnóstico do volume e forma de descarte de óleos e gorduras residuais por parte dos contemplados. Foi realizado o cálculo amostral, resultando em 35 pessoas para amostra desta pesquisa. Foi aplicado um questionário com 10 questões onde foram avaliados a idade, a escolaridade, o volume de óleos gerados por residência e a percepção dos participantes sobre os impactos e forma correta de descarte dos Óleos e Gorduras Residuais (OGR). Depois desse levantamento, foi realizada uma oficina para explicar as formas de disposição correta e os impactos do descarte no solo ou nas pias. Foi aplicado um segundo questionário para avaliar o aprendizado dos participantes. Estima-se que sejam gerados 46,5 litros de OGR por mês nas residências participantes que, se descartado de forma incorreta, podem poluir 930.000 litros de água. A oficina teve um impacto positivo na mudança de atitude dos participantes, visto que os moradores reduziram o descarte no solo e no ralo em $11 \%$ e houve um aumento de $17 \%$ na doação de OGR.
\end{abstract}

Palavras-chaves: Descarte de Óleo. Educação Ambiental. Impactos dos óleos e gorduras. Poluição da água.

\section{RECYCLING OF RESIDUAL OIL AND FATS: PERCEPTION OF THE ENVIRONMENTAL IMPACT BY RESIDENTIAL CONDOMINIUM RESIDENTS IN FORTALEZA, BRAZIL}

\begin{abstract}
Considering that the oils' and fats' disposal causes several negative impacts, especially with water and soil pollution and impacts on the sanitation infrastructure, it is necessary that the population take notice of the reuse forms and proper disposal of this waste. This paper aims promote a change in the habits of residents in a condominium in the city of Fortaleza through training and a diagnosis of the volume and form of disposal of residual oils and fats by those contemplated. The sampling calculation was performed resulting in 35 people for the sample of this research. A questionnaire with 10 questions was applied, where age, education, the volume of oils generated per residence and the participants' perception about the impacts and correct way of disposing of fat oils were all evaluated. After the survey a workshop was held to explain the correct disposal methods and the disposal impacts on the ground or in sinks. A second questionnaire was issued to assess the participants' learning. It is estimated that 46.5 liters of Residual Oils and Fats are generated per month in participating households which if disposed incorrectly could pollute 930,000 liters of water. The workshop had a positive impact on changing participants' behavior, as residents reduced land and drain disposal by $11 \%$ and there was a $17 \%$ increase in Oils' and Fats' Residual donation.
\end{abstract}

Keywords: Oil Disposal. Environmental education. Oils and fats Impacts. Water pollution.

\section{INTRODUÇÃO}

É fato que todas as atividades humanas geram resíduos e que essa geração está associada diretamente à economia de uma nação e à produção de insumos.
Logo, é uma preocupação cada vez maior a redução do consumo para consequentemente reduzir os resíduos gerados, aumentando a vida útil de aterros sanitários e facilitando a extinção dos lixões (CAMPOS, 2012. 
RECICLAGEM DE ÓLEOS E GORDURAS RESIDUAIS: PERCEPÇÃO DO IMPACTO AMBIENTAL POR MORADORES DE CONDOMÍNIO RESIDENCIAL EM FORTALEZA/CE

NORBERTO et al., 2021).

Entre os resíduos que necessitam de tratamento adequado e que prejudicam a vida útil de aterros e a qualidade do solo e dos recursos hídricos, estão os Óleos e Gorduras Residuais (OGR), muito utilizados na culinária. Podem ser classificados de acordo com a NBR 10.004 de 2004, como Classe II B, por seus componentes não solubilizarem em água deixando-a com padrões superiores aos padrões de potabilidade (ABNT, 2004).

Apesar de óleos e gorduras serem tratados como sinônimos, vale ressaltar que suas origens são diferentes, sendo o primeiro de origem vegetal, que apresenta como principal propriedade o estado líquido em temperatura ambiente, o que se deve a predominância de ácidos graxos insaturados, enquanto as gorduras são de origem animal, apresentando estado sólido em temperatura ambiente pela predominância de ácidos graxos saturados (IBSCH; SOUZA; REITER, 2018).

Pela escassez de normas ou baixa especificidade das legislações vigentes acerca do descarte de OGR, os seus destinos são comumente a rede de esgoto, o solo e os corpos hídricos (AMARAL et al., 2016). Apesar de ser passível de biodegradação e estar classificado como resíduos não perigosos, os OGR precisam de temperaturas altíssimas e $\mathrm{pH}$ básico no solo para serem degradados, características não encontradas naturalmente. Além disso, quando descartados diretamente no solo ou em aterros sanitários, podem causar impermeabilização e poluição de lençóis freáticos, além de afetarem a composição química do solo, prejudicando o desenvolvimento da vegetação (Thode Filho et al., 2020).

Quando o descarte se dá nos ralos de pias e banheiros, por sua insolubilidade em água e baixa densidade, seu acúmulo na superfície dificulta as trocas de gases entre a água e a atmosfera, causando danos à vida aquática e aos diversos ecossistemas. Além de danos ambientais, causam prejuízos às redes coletoras de esgoto, provocando a retenção de sólidos, entupimentos e problemas de drenagem (AMARAL et al. 2016).

A Política Nacional dos Resíduos Sólidos (PNRS) define resíduos sólidos como qualquer material, substância, objeto ou bem descartado resultante de atividades humanas em sociedade, incluindo materiais em estados sólido ou semissólido, gases e líquidos. Tratandose do objeto desta pesquisa, o óleo de cozinha, a política não deixa clara sua destinação e tratamento, mas é instituída a responsabilidade compartilhada entre produtores e consumidores, havendo embasamento para a necessidade de participação da população nesse processo (BRASIL, 2010).

Tratando-se da legislação específica para descarte dos óleos residuais, a nível federal, a Lei no 9.605/1998 e o Decreto $n^{\circ} 6.514 / 2008$ tratam de penalidades para aquele que lançar, entre outros resíduos, substâncias oleosas fora dos padrões legais (BRASIL, 1998). Quanto a esses padrões, quem estabelece é o Conselho Nacional do Meio Ambiente (Conama), que define, na Resolução n 230 de 2011, que o lançamento de efluentes tratados deve atingir até $50 \mathrm{mg} / \mathrm{L}$ de óleos vegetais e gorduras animais (CONAMA, 2011).

No panorama nacional, há poucos estados com legislações específicas para tratamento e logística reversa do óleo residual e não há incentivo dos órgãos ambientais para pressionar empresas produtoras de óleo a se responsabilizarem pelos resíduos pós-consumo, apontando para apenas $38 \%$ com programas de incentivo ou apoio a programas de recolhimento do óleo (SILVA; HECK, 2020).

Em nível estadual, o Ceará dispõe da Lei 16309, de 03 de agosto de 2017, que conta com apenas cinco artigos, estabelecendo que empreendimentos que trabalham com refeição em geral, independente do seu porte, e que possuam manuseio de óleos vegetais de cozinha no preparo de alimentos, precisam realizar o descarte adequadamente, mas a norma sequer orienta como deve ser esse descarte (CEARÁ, 2017).

A atenção legal quanto ao descarte de OGR é desproporcional ao impacto causado por esses resíduos. A Companhia de Saneamento Básico do Estado de São Paulo - SABESP (2011) estima que um litro de óleo descartado incorretamente pode esgotar o oxigênio de até 20 mil litros de água e aumentar em $45 \%$ os custos no tratamento do esgoto.

Para que os impactos dos óleos sejam reduzidos, há ao menos duas formas de tratamento. A primeira é o seu reaproveitamento na produção de biodiesel e a segunda forma é a produção de sabões e detergentes. Infelizmente por falta de tecnologias e de capacidade de coleta e transporte dos óleos residuais de residências e unidades comerciais, se torna inviável até então o reaproveitamento do OGR na produção do Biodiesel. Há pesquisas que propõem soluções quanto à tecnologia de pré-tratamento dos óleos de fritura, uma das deficiências nos processos de aproveitamento de OGR, mas para que haja investimento e aplicação dessa tecnologia, é necessário esforço público para coleta (MARINS; SANTOS; ALIMENTOS, 2017).

De acordo com a Associação de Produtores de Biocombustíveis do Brasil - APROBIO (2017), são reciclados 30 milhões de litros de óleo de cozinha no Brasil para produção do biodiesel, mas não se sabe ao certo o quanto isso representa em percentual de óleo gerado nas residências e pontos comerciais.

Uma alternativa adotada em todo o Brasil para a 
RECICLAGEM DE ÓLEOS E GORDURAS RESIDUAIS: PERCEPÇÃO DO IMPACTO AMBIENTAL POR MORADORES DE CONDOMÍNIO RESIDENCIAL EM FORTALEZA/CE

coleta seletiva e que é utilizada para a coleta de óleo é a criação de Pontos de Entrega Voluntários (PEVs), possibilitando o recebimento direto da população e articulação com organizações para encaminhamento ao tratamento adequado. Porém, dependem de forma direta da educação e atitude dos consumidores, o que ainda representa um desafio na operacionalização dessa rota tecnológica e destinação (ANTUNES; CAMPOS. 2018).

Na cidade de Fortaleza, há um projeto de PEVs chamado de EcoPontos e também associações de catadores que recebem óleo de fritura. Eles recolhem o óleo e encaminham à Estação de Coleta e Beneficiamento, localizada no bairro Serrinha, onde são retiradas as impurezas. Após o pré-tratamento, o óleo segue para a Usina de Biodiesel de Quixadá. A unidade pode processar até 170 milhões de litros de óleo por ano. A iniciativa é uma parceria entre a Petróleo Brasileiro S.A (Petrobras) e o Serviço Brasileiro de Apoio às Micro e Pequenas Empresas (Sebrae) (Prefeitura de Fortaleza 2020).

Além dos ecopontos, várias escolas municipais foram contempladas com Pontos de Entrega Voluntária (PEV) de resíduos, batizados de Espaços Reciclando Atitudes, e que, além de resíduos recicláveis, incluem coletores de óleo usado.

Uma outra possibilidade de destinação desses óleos é o aproveitamento e reciclagem do OGR na produção de sabões e detergentes em fábricas ou até mesmo em residências. O processo consiste em transformar as moléculas de gordura em moléculas solúveis em água, por meio da adição de hidróxido de sódio, chamada reação de saponificação (SOARES, 2016), descrita na equação química da Figura 1

Figura 1: Reação de saponificação.

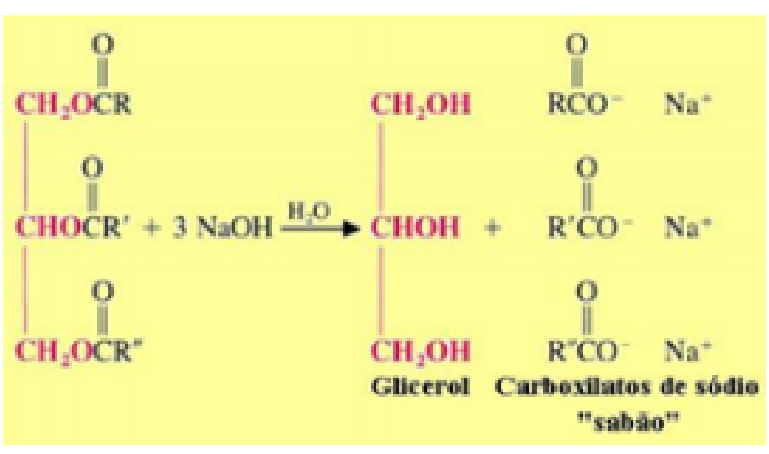

Fonte: Soares (2016).

Corrêa et al. (2018) realizaram uma pesquisa com 58 moradores de um condomínio residencial em Campos dos Goytacazes no Rio de Janeiro e verificaram que apenas $24 \%$ dos moradores entregam o óleo residual em PEVs e $2 \%$ reciclam, enquanto os outros $74 \%$ descartam de forma incorreta, estimando-se uma poluição de aproximadamente 145.000 litros de água por mês.

De acordo com a pesquisa de Weyer e Nora (2015), cuja amostra foi de 250 residências do bairro Morada da Serra Três Setor Quatro - Cuiabá/MT, 63\% afirmam descartar o OGR diretamente no ralo ou em recipientes levando à coleta comum. Foram estimados 2,872 litros de óleo gerados por mês por família e estimando-se 57.400 litros de água poluída.

Assim como os demais autores, Costa et al. (2017) identificaram a importância da educação ambiental no processo de conscientização da população e também para apoio à coleta seletiva do OGR. Nas cidades de Quixadá e Quixeramobim, realizou-se uma palestra com participação de 12 unidades comerciais e se propôs o recolhimento do óleo para entrega a uma indústria de biodiesel. Apesar de $90 \%$ terem realizado a entrega do óleo aos pesquisadores, os demais realizaram o reaproveitamento ou entregaram por conta própria a pessoas que realizariam a reciclagem do óleo, logo, houve um impacto positivo em $100 \%$ da população da pesquisa.

Considerando os impactos negativos sobre água, solo e infraestrutura da rede de saneamento, descritos anteriormente, e perante a falta de orientação da legislação nacional e estadual, a importância deste estudo se reflete na mudança de hábitos de descarte dos OGR pelos sujeitos da pesquisa, bem como geração de dados para futuros trabalhos, motivando a educação ambiental na busca pelo aproveitamento econômico de OGR.

A presente pesquisa visa realizar o diagnóstico do volume e forma de descarte de OGR em um condomínio residencial da cidade de Fortaleza, promovendo educação quanto aos impactos e forma correta de descarte e possibilitando a mudança de hábitos dos sujeitos contemplados.

\section{MATERIAIS E MÉTODOS}

Foram aplicados 35 questionários e os participantes foram convidados para a Oficina de Reúso de OGR, como segundo momento da pesquisa.

Este trabalho apresenta os resultados de uma pesquisa quali-quantitativa com uso de questionário semiestruturado. A população da pesquisa é representada por 45 pessoas, um representante de cada residência do condomínio. Foi utilizado o método de amostragem adaptado de Levin (1987), utilizando a Equação 1 para definir o tamanho da amostra.

$$
n=\frac{N \times Z^{2} \times p \times(1-p)}{(N-1) \times e^{2}+Z^{2} \times p \times(1-P)}
$$


RECICLAGEM DE ÓLEOS E GORDURAS RESIDUAIS: PERCEPÇÃO DO IMPACTO AMBIENTAL POR MORADORES DE CONDOMÍNIO RESIDENCIAL EM FORTALEZA/CE

Onde: $n$ tamanho da amostra procurada; $N$ tamanho da população; $Z$ variável normal crítica padronizada associada ao nível de confiança; $p$ probabilidade verdadeira de ocorrência do evento e $e$ erro amostral.

Nesta pesquisa foi adotado o valor de Z como 1,645 para nível de confiança de $90 \%$, admitindo um erro amostral de $6,65 \%$ e adotando p padrão de $50 \%$, visto que a probabilidade verdadeira do evento é desconhecida. A partir disso a amostra a ser estudada é de 35 indivíduos.

O questionário coletou dados sobre idade, escolaridade, o volume e a forma de descarte dos OGR dos sujeitos. Considerando o momento de pandemia e para que houvesse a máxima segurança da pesquisadora e dos participantes, a aplicação dos questionários aconteceu de forma individual, nas residências dos participantes e de forma virtual, com auxílio do Google Forms.

Os dados foram analisados e, após a obtenção dos resultados, foram realizadas oficinas cerca de duas semanas após a aplicação dos questionários, na tentativa de melhorar os índices de conhecimento sobre o tema e buscando mudar a forma de descarte dos OGR. Devido à situação de pandemia, foi necessário dividir a amostra em três turmas, evitando aglomerações. As oficinas aconteceram no condomínio em agosto de 2021, direcionadas à divulgação dos impactos negativos do descarte de OGR sobre as formas adequadas de destinação e reaproveitamento. Evitando aglomeração, foram criadas três turmas, nos dias 13, 14 e 15 de agosto, respectivamente às $16 \mathrm{~h}$, às $20 \mathrm{~h}$ e às $19 \mathrm{~h}$, com uma hora de duração.

Para este trabalho foram considerados como impactos mais relevantes e diretos do descarte incorreto de OGR: a poluição da água, do solo e entupimento de encanamentos, com nível de relevância nessa ordem.

Foi aplicado um segundo questionário para os participantes da oficina a fim de avaliar a importância da atividade e para medir a mudança de hábito deles. Por fim, foram associados os dados anteriores à atividade educativa com escolaridade, bem como com os resultados de percepção dos sujeitos após a oficina.

\section{RESULTADOS E DISCUSSÕES}

A respeito das idades dos participantes, temos: entre 37 e 45 anos $(25,7 \%)$, de 46 a 50 anos $(22,9 \%)$ ou acima de 50 anos de idade $(22,9 \%)$. Os demais participantes se dividiam entre 18 a 36 anos de idade (28,6\%). Tratando-se da escolaridade, a maioria possuía ensino médio completo $(31,4 \%)$, seguidos de ensino fundamental incompleto $(25,7 \%)$ e ensino superior completo $(25,7 \%)$ ou incompleto $(22,9 \%)$.
Para este trabalho, a escolaridade pode indicar o quanto a forma de descarte está relacionada à educação formal ou simplesmente com a cultura da população, o que foi analisado a seguir.

Os participantes foram questionados sobre o nível de preocupação com o tipo de descarte e seus impactos, e positivamente $68,6 \%$ deles responderam que se preocupam muito com o descarte, enquanto apenas $22,9 \%$ afirma se preocupar um pouco e apenas $8,6 \%$ afirmou não ter essa preocupação com o descarte de óleos. Acredita-se então que pelo menos a maioria que afirmou ter preocupação poderá ser impactada mais facilmente pela oficina. O que pode causar a falta de preocupação das pessoas quanto ao descarte de óleo é a falta de conhecimento sobre suas consequências para a saúde coletiva.

Em seguida, os participantes foram convidados a escolher qual a principal forma de descarte de seus resíduos de OGR, sendo os valores expressos no Gráfico da Figura 2 a seguir. Vale ressaltar que nessa questão foi possível escolher até 3 opções.

Figura 2: Forma de descarte de óleos e gorduras em cada residência.

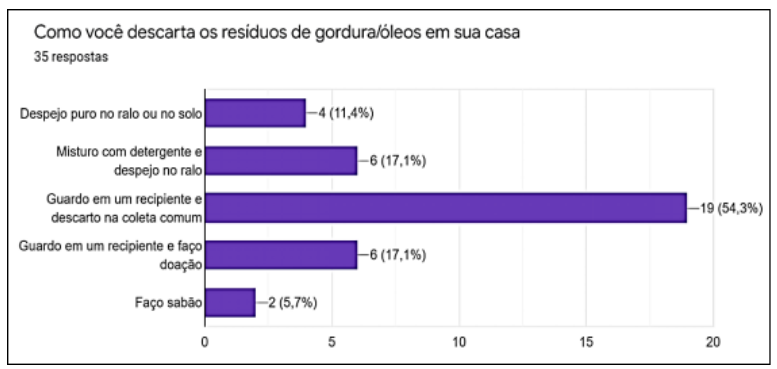

Um dado importante a se analisar é o volume de OGR descartado, para calcular o tipo de impacto que o volume poderá causar e medir a relevância deste trabalho na educação ambiental da população do estudo. A estimativa de óleo gerado em cada família foi descrita no Gráfico da Figura 3

Figura 3: Volume de óleo gerado por mês por residência.

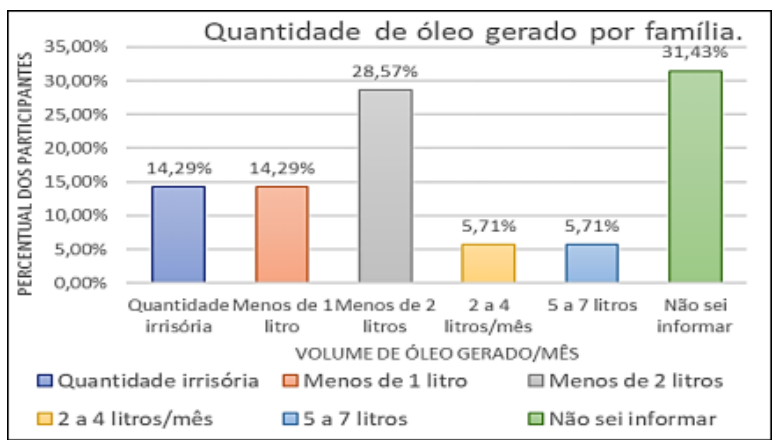


RECICLAGEM DE ÓLEOS E GORDURAS RESIDUAIS: PERCEPÇÃO DO IMPACTO AMBIENTAL POR MORADORES DE CONDOMÍNIO RESIDENCIAL EM FORTALEZA/CE

\begin{abstract}
A maioria dos participantes $(31,43 \%)$ não sabia informar quanto de óleo gerava em suas residências. Outra parcela maior informou gerar menos de 2 litros. Assim, por meio de estimativas, é possível inferir quanto seria gerado por mês no condomínio. Considerando que aqueles que não sabem informar o volume gerem pelo menos 1 litro por mês e desconsiderando os participantes que geram quantidades irrisórias, temos aproximadamente 46,5 L/mês gerados no condomínio, capazes de contaminar 930.000 litros de água, ou ainda contaminar o solo e reduzir a vida útil dos aterros, visto que boa parte dos residentes descartam o óleo na coleta comum.
\end{abstract}

Entre as formas de reduzir o consumo de óleo está o reúso em outras frituras, se bem conservado. Dos moradores, $65,7 \%$ afirmaram reusar de uma a três vezes os óleos, e 2,9\% afirmaram só reusar a gordura de origem animal, o que já representa uma redução relevante de consumo e consequentemente de descarte. Apenas $31,4 \%$ informou que não faz reúso.

Quando foram questionados sobre seu nível de conhecimento acerca dos prejuízos do descarte incorreto de óleos, os dados gerados resultaram no Gráfico da Figura 4

Figura 4: Nível de conhecimento sobre descarte de OGR antes da oficina.

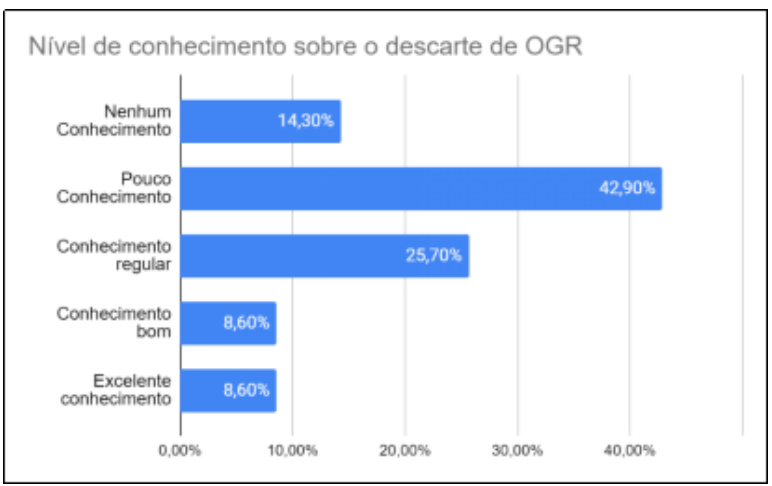

É perceptível no Gráfico da Figura 4 que a maioria dos participantes (43\%) afirmou ter pouco conhecimento ou conhecimento regular $(26 \%)$ sobre os prejuízos do descarte incorreto, ressaltando a importância do processo de educação desse público.

Para entendermos o que é esse nível de conhecimento na prática, é possível verificar o que os participantes consideram como forma correta de descarte de OGR, por meio da interpretação do Gráfico da Figura 5

No questionário os participantes poderiam escolher quantas opções desejassem. Assim, apesar do fato de alguns moradores escolherem opções sem relevância,
Figura 5: Opinião sobre impactos do descarte incorreto de OGR antes da oficina.

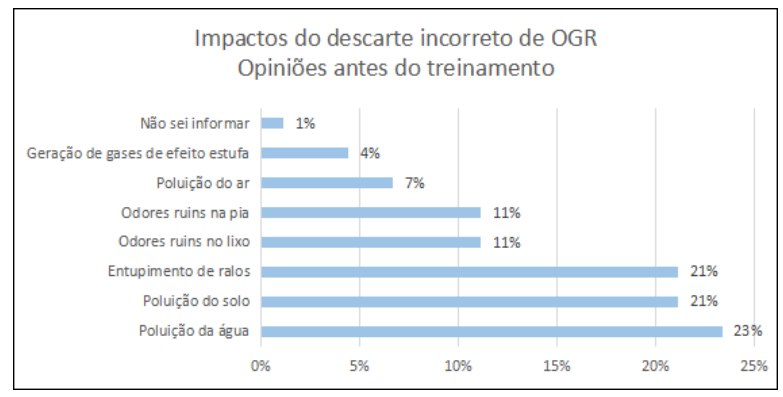

como "odores ruins na pia ou no lixo", "poluição do ar" e "geração de gases de efeito estufa", a maioria também escolheu aqueles considerados principais. Esperava-se que, após a oficina, os valores se concentrassem naqueles impactos considerados relevantes.

Foi realizada uma análise para verificar a relação entre escolaridade e a forma de descarte. Para isso, foi estabelecido um sistema de notas e, para chegar ao Valor do Indicador, multiplicou-se a nota da opção pelo percentual de participantes de uma escolaridade.

Os maiores indicadores estão relacionados aos níveis a partir do superior incompleto, mas os participantes de nível médio incompleto e completo tiveram notas muito próximas.

Finalizando a análise das respostas do questionário aplicado antes da oficina, os participantes da pesquisa foram questionados sobre quais seriam as melhores formas de descarte e aproveitamento dos OGR. Os resultados foram apresentados no Gráfico da Figura 6

Figura 6: Opinião sobre impactos do descarte incorreto de OGR antes da oficina.

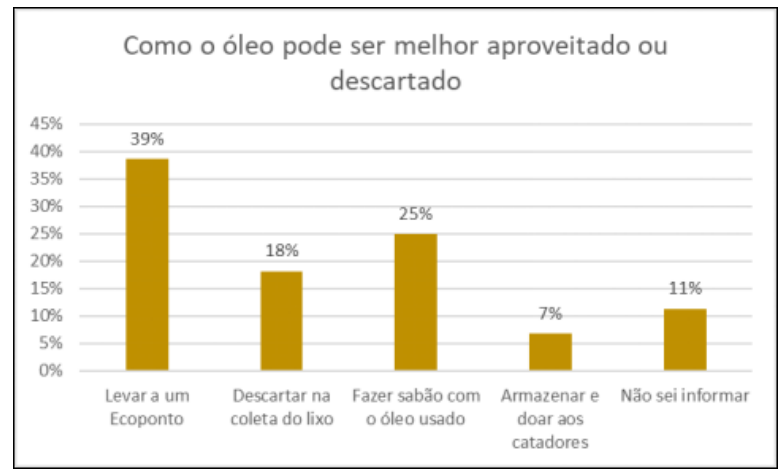

É interessante observar que $39 \%$ dos moradores que responderam a pesquisa sabem que a destinação ideal dos óleos seria o Ecoponto, mas 54,3\% descartam na coleta comum. Vale questionar o que leva as pessoas a descartar de forma errada, apesar de conhecer o des- 
RECICLAGEM DE ÓLEOS E GORDURAS RESIDUAIS: PERCEPÇÃO DO IMPACTO AMBIENTAL POR MORADORES DE CONDOMÍNIO RESIDENCIAL EM FORTALEZA/CE

Tabela 1: Relação entre escolaridade e forma de descarte.

\begin{tabular}{cccccccc}
\hline Tipo de Descarte & Nota & EFC & EMI & EMC & ESI & ESC & PMD \\
\hline Despejo puro no ralo ou no solo & 1 & $100 \%$ & & $27 \%$ & $12,50 \%$ & & \\
Despejo no ralo com detergente & 2 & & $50 \%$ & $9 \%$ & $12,50 \%$ & $11,11 \%$ & \\
Descarto na coleta comum & 3 & & $50 \%$ & $36 \%$ & $37,50 \%$ & $77,78 \%$ & $100 \%$ \\
Faço doação & 4 & & & $18 \%$ & $37,50 \%$ & $11,11 \%$ & \\
Faço sabão & 4 & & & $9 \%$ & & & \\
\hline Valor do Indicador & & 1,00 & 2,50 & 2,64 & 3,00 & 3,00 & 3,00 \\
\hline
\end{tabular}

Legenda: EFC: Ensino Fundamental Completo; EMI: Ensino Médio Incompleto; EMC: Ensino Médio Completo; ESI: Ensino Superior Incompleto; ESC: Ensino Superior Completo; PMD: Pós/Mestrado/Doutorado.

carte ideal.

Quanto à dificuldade de entender o conteúdo, $85,7 \%$ dos participantes consideraram o conteúdo de fácil aprendizagem, atribuindo notas de 8 a 10 para o treinamento, enquanto os demais deram notas abaixo de 7 . Quanto à importância do tema abordado, 91,2\% consideraram que o conteúdo é extremamente importante (nota 10), enquanto apenas 5,9\% atribuíram nota 9 e outros $2,9 \%$ atribuíram nota 7 .

Sendo questionados novamente sobre o nível de conhecimento sobre o tema do descarte de OGR e seus impactos, após o treinamento, foi percebido um aumento no nível de conhecimento, como esperado. Os dados foram descritos no Gráfico da Figura 7 .

Figura 7: Nível de conhecimento dos impactos do descarte incorreto de OGR após a oficina.

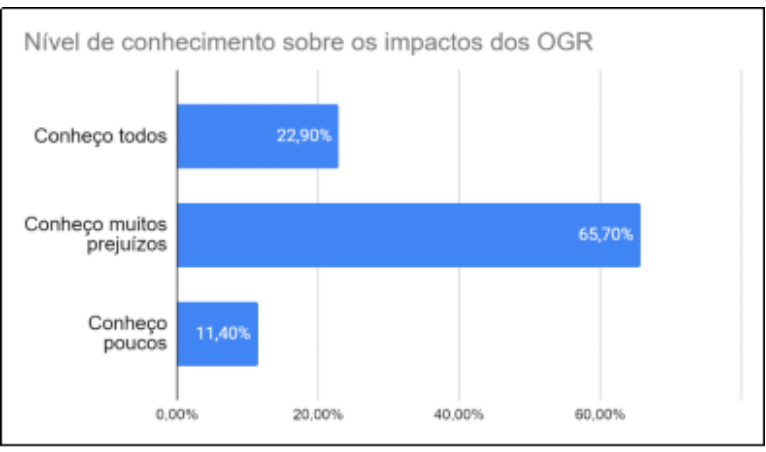

Comparando o Gráfico da Figura 7 com o Gráfico da Figura 4, foi observada uma inversão, onde antes do treinamento a maioria dos participantes considerava ter pouco conhecimento sobre o tema, agora $65,7 \%$ consideram conhecer muitos prejuízos do descarte incorreto e apenas $11,4 \%$ conhecer pouco. Esse é um dos impactos positivos decorrentes da oficina.

Quando foram questionados sobre os impactos do OGR, após o conhecimento adquirido, foi perceptível que as pessoas passaram a considerar outros impactos que antes não eram percebidos. Os principais impactos como poluição da água, do solo e entupimento de ralos, permaneceram como os mais percebidos, mas houve um aumento significativo da escolha por geração de gases de efeito estuda e poluição do ar, conforme Gráfico da Figura 8

Figura 8: Nível de conhecimento dos impactos do descarte incorreto de OGR após a oficina.

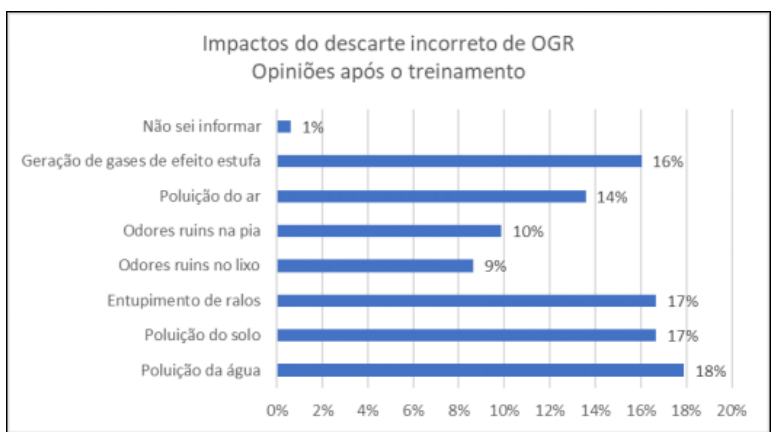

O Gráfico da Figura 8 indica a eficiência da oficina em informar os impactos negativos do descarte incorreto dos OGR e possivelmente na importância desse treinamento para a mudança de atitude da população desse estudo. Dos participantes, $82,9 \%$ afirmaram ter mudado a forma que descarta seus resíduos, enquanto os outros $17,1 \%$ afirmaram manter a forma de descarte, não necessariamente descarte incorreto. Para entender como ocorreu essa mudança, vale analisar e comparar as formas de descarte antes e depois da oficina. O Gráfico da Figura 9 representa a nova forma de descarte dos OGR pelos participantes.

Foi estimada uma capacidade poluente de 930.000 litros de água com os aproximadamente 46,5 litros de OGR gerados nas residências do condomínio antes do treinamento realizado. Houve um aumento significativo de pessoas fazendo doação de OGR, em torno de $17 \%$, ao mesmo tempo em que houve redução no número de pessoas que fazem o descarte no ralo de $11 \%$. Os participantes relataram que sabem a importância de levar o 
RECICLAGEM DE ÓLEOS E GORDURAS RESIDUAIS: PERCEPÇÃO DO IMPACTO AMBIENTAL POR MORADORES DE CONDOMÍNIO RESIDENCIAL EM FORTALEZA/CE

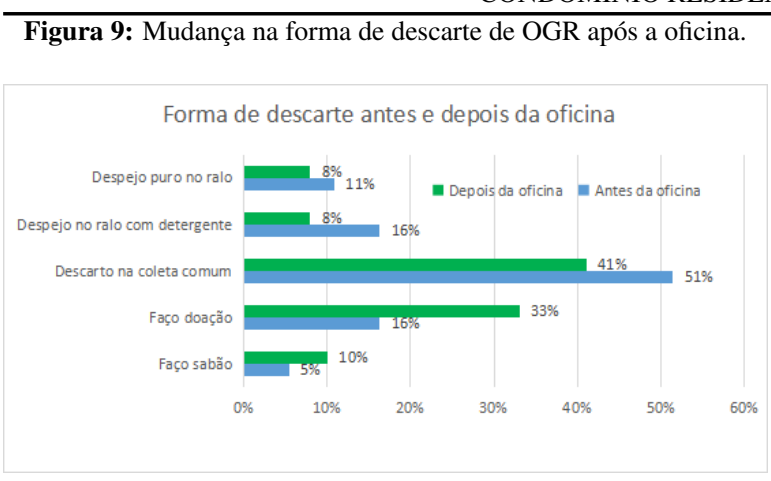

OGR ao Ecoponto, mas por ser distante do condomínio, nem todas as pessoas têm acesso a essa destinação.

Interessante apontar a fala de uma participante que, além de fazer sabão, realiza outras formas de reúso e é um excelente exemplo de cuidado com o meio ambiente e com a saúde:

\begin{abstract}
"Separo em dois vidros o óleo de gorduras de carnes em um e o óleo de toucinho em outro vidro o óleo mais limpo que é o de torresmo ou toicinho eu reutilizo mais uma vez e depois guardo o restante para fazer sabão e quando vou acender o carvão quando vou assar alguma coisa na churrasqueira, e o resto faço sabão e consumo óleo muito pouco, uso mais óleo de origem animal o azeite extra virgem o óleo de coco e manteiga."
\end{abstract}

Espera-se que as pessoas mantenham a mudança positiva e que possam incentivar melhorias inclusive ao público que não participou desse projeto.

\section{CONSIDERAÇÕES FINAIS}

Após o treinamento, será possível reduzir essa poluição a longo prazo, visto que a amostra dessa pesquisa passou por um processo de educação eficiente, o que pode ser confirmado com o aumento de pessoas realizando doação de OGR. Houve uma redução de $11 \%$ no descarte direto no ralo, que é uma das formas mais preocupantes por impactar diretamente a rede de tratamento e os recursos hídricos.

Identificou-se que há uma fraca relação entre o nível de escolaridade e a forma de descarte dos resíduos. Sugere-se realizar essa pesquisa com outras variáveis, como idade ou poder aquisitivo, além de selecionar uma amostra maior para estudo.

\section{REFERÊNCIAS}

ABNT. NBR 10.004: Resíduos Sólidos Classificação. 2. ed. Rio de Janeiro: Associação Brasileira De Normas Técnicas, 2004. 71 p.

AMARAL, T. S. d.; BESS, M. V.; KAPELINSKI, C. T.; MARTINS, T. M.; SCREMIN, O. B.
Reaproveitamento de óleos e gorduras como ação minimização de impactos ambientais. In: ANAIS... Mostra interativa da produção estudantil em educação científica e tecnológica - O protagonismo estudantil em foco. Ijuí: Unijui, 2016. v. 2, p. 1-5.

ANTUNES, M. C.; CAMPOS, T. M. P. de. Cadeia reversa do óleo de cozinha residual: o papel do ponto de entrega voluntária (pev). Dignidade Re-Vista, v. 3, n. 5, p. 96-111, 2018.

APROBIO. Brasil recicla 30 milhões de litros de óleo de cozinha na produção de biodiesel. 2017. Disponível em: <https://aprobio.com.br/noticia/ brasil-recicla-30-milhoes-de-litros-de-oleo-del -cozinha-na-producao-de-biodiesel>. Acesso em: 10 jun. 2021.

BRASIL. Lei no 9605, de 12 de fevereiro de 1998. Dispõe sobre as sanções penais e administrativas derivadas de condutas e atividades lesivas ao meio ambiente, e dá outras providências. Brasília, DF: Diário Oficial [da] República Federativa do Brasil, 1998. Disponível em: <http: //www.planalto.gov.br/ccivil_03/leis/19605.htm> Acesso em: 03 jul. 2019.

Lei $\mathrm{n}^{\circ} \mathbf{1 2 . 3 0 5}$, de 2 de agosto de 2010 . Institui a Política Nacional de Resíduos Sólidos; altera a Lei no 9.605, de 12 de fevereiro de 1998; e dá outras providências. Brasília, DF: Diário Oficial [da] República Federativa do Brasil, 2010. Disponível em: <http://www2.mma.gov.br/port/conama/legiabre.cfm? codlegi=636> Acesso em: 03 jul. 2019.

CAMPOS, H. K. T. Renda e evolução da geração per capita de resíduos sólidos no brasil. Engenharia Sanitária e Ambiental, SciELO Brasil, v. 17, n. 2, p. 171-180, 2012.

CEARÁ. Lei no 16309, de 03 de agosto de 2017. Dispõe sobre medidas de coleta e reciclagem de óleos e gorduras usados, de origem vegetal e animal de uso culinário e seus resíduos a fim de minimizar os impactos ambientais que seu despejo inadequado pode causar. Fortaleza: Diário Oficial do Estado do Ceará, 2017. Disponível em: <https: //www.legisweb.com.br/legislacao/?id=347365> Acesso em: 03 jul. 2019.

CONAMA. Resolução no 430 , de 13 de maio de 2011. Dispõe sobre as condições e padrões de lançamento de efluentes, complementa e altera a Resolução de $n^{0}$ 357, de 17 de março de 2005, do Conselho Nacional do Meio Ambiente - CONAMA. Brasília: 
RECICLAGEM DE ÓLEOS E GORDURAS RESIDUAIS: PERCEPÇÃO DO IMPACTO AMBIENTAL POR MORADORES DE CONDOMÍNIO RESIDENCIAL EM FORTALEZA/CE

Diário Oficial [da] República Federativa do Brasil, 2011. Disponível em: <http://www2.mma.gov.br/port/ conama/legiabre.cfm?codlegi=646> Acesso em: 03 jul. 2019.

CORRÊA, L. P.; GUIMARÃES, V. N.; HESPANHOL, L. I.; SILVA, J. V. Impacto ambiental causado pelo descarte de óleo: estudo do destino que é dado para o óleo de cozinha usado pelos moradores de um condomínio residencial em campos dos goytacazes-rj. Revista Brasileira de Planejamento e Desenvolvimento, Universidad Tecnológica Federal Paraná, v. 7, n. 3, p. 341-352, 2018.

COSTA, D. R.; OLIVEIRA, G. F. d.; SOUSA, A. G. L.; SOUZA, J. G. M. d.; MATTOS, S. H. Responsabilidade sociambiental: o redirecionamento do óleo de cozinha na preservação dos recursos hídricos do sertão central do ceará. In: CONGRESSO BRASILEIRO DE GESTÃO AMBIENTAL. Campo Grande: CONGEA, 2017. (8), p. 1-4.

IBSCH, R. B. M.; SOUZA, C. K. de; REITER, M. G. R. Óleos e gorduras vegetais não são todos iguais. International Journal of Nutrology, Thieme Revinter Publicações Ltda, v. 11, n. S 01, p. Trab611, 2018.

LEVIN, J. Estatística aplicada a ciências humanas. In: 2. ed. São Paulo: Editora Harbra Ltda, 1987.

cap. 7. Amostras e Populações, p. 100-123.

MARINS, D. S.; SANTOS, M. E.; ALIMENTOS, T. em. Pré-tratamento do óleo residual de fritura para elevação de ph e diminuição de sólidos para a produção de biodiesel. Revista da União Latino-americana de Tecnologia, v. 1, n. 5, p. 1-20, 2017.

NORBERTO, A. S.; LIRA, S. A.; NASCIMENTO, A. V. do; DUARTE, A. D.; SILVA, J. G. C. da; ALVES, J. V. C.; PEDROSA, T. D.; NETO, J. F. de O. Estudo da relação entre a geração de resíduos sólidos urbanos e o produto interno bruto (pib) per-capito no brasil. Research, Society and Development, v. 10, n. 1, p. 1-14, 2021.

Prefeitura de Fortaleza. Escola no bairro Sabiaguaba é contemplada com Espaço Reciclando Atitudes e Ponto de Entrega Voluntária (PEV). 2020. Disponível em: $<$ https://www.fortaleza.ce.gov.br/noticias/ escola-no-bairro-sabiaguaba-e-contemplada-coml -espaco-reciclando-atitudes-e-ponto-de-entregal -voluntaria-pev> Acesso em: 06 jun. 2021.
SABESP. Reciclagem de óleo. 2011. Disponível em: $<$ http://site.sabesp.com.br/site/interna/Default.aspx? secaold=82>. Acesso em: 20 ago. 2021.

SILVA, J. D.; HECK, M. Panorama da logística reversa do óleo residual de fritura no brasil. Revista Gestão \& Sustentabilidade Ambiental, v. 9, n. 1, p. 720-739, 2020 .

SOARES, A. S. Produção do sabão a partir do óleo de cozinha pós-fritura. In: Congresso Nacional de Pesquisa e Ensino em Ciências. Campina Grande: Editora Realize, 2016. v. 1, p. 1-10.

Thode Filho, S.; CALDERARI, M. R. d. C. M.; PEREZ, D. V.; PAIVA, J. L. de; SOUZA, P. S. A. de; CERQUEIRA, A. A. Efeitos associados ao descarte inadequado do óleo vegetal residual nas propriedades físico-químicas do solo. Natural Resources, v. 10, n. 3, p. 25-37, 2020.

WEYER, M.; NORA, G. D. Resíduos sólidos domésticos: estudo de caso do óleo vegetal residual no bairro morada da serra cuiabá/mt. Revista Geonorte, v. 6, n. 24 , p. $62-80,2015$. 